REVESCO. Revista de Estudios Cooperativos

ISSN: $1885-8031$

https://dx.doi.org/10.5209/REVE.78537

\title{
Análisis del marco jurídico del voluntariado de empresa en España ${ }^{1}$
}

\author{
Ana Lor Serrano ${ }^{2}$ y Luisa Esteban Salvador ${ }^{3}$
}

Recibido: 13 de marzo de 2021 / Aceptado: 13 de septiembre de 2021 / Publicado: 22 de noviembre de 2021

Resumen. Tras delimitar el concepto de voluntariado de empresa, este trabajo se centra en analizar su marco legislativo externo e interno. En un primer momento se examinan las recomendaciones sobre el voluntariado de empresa en el ámbito supranacional o externo, dado que en él se desarrollan pautas que establecen las bases a seguir en los niveles inferiores. Posteriormente se enfoca en su desarrollo nacional o interno, y para ello se comienza por analizar la normativa española y se continúa con la observación de la autonómica. Cabe destacar que después de seis años desde que viera la luz la Ley 45/2015, de 14 de octubre, de voluntariado, todavía está pendiente de aprobación su desarrollo reglamentario, y aunque se ha avanzado en el proyecto de Real Decreto, se podrían aportar mejoras antes de su publicación. Con este fin se ha analizado su contenido, y se hacen propuestas de modificaciones que acercarían la regulación a las indicaciones de organismos internacionales, para así diferenciar el voluntariado tradicional del corporativo o de empresa. Por otro lado, dada la diversidad de normativas en las diferentes comunidades autónomas se considera interesante examinar su grado de uniformidad entre ellas, y si han mejorado o restringido la legislación estatal. La finalidad de esta comparación es contrastar posibles divergencias en los distintos marcos regulatorios. Con el fin de presentar un estudio completo sobre las diferentes actuaciones, se mostrarán los distintos planes o estrategias de voluntariado corporativo desarrollados en el ámbito estatal y autonómico español, así como la presentación que del voluntariado se hace en los mismos.

Palabras clave: Voluntariado de empleados; Voluntariado Corporativo; Estrategias de voluntariado; Personal empleado; Comunidades Autónomas.

Claves Econlit: K31; K30; M0.

\section{[en] Analysis of the legal framework on corporate volunteering in Spain}

Abstract. After defining company volunteering, this work focuses on analyzing its external and internal legislative framework. At first, the recommendations on company volunteering in the supranational or external sphere are examined since it develops guidelines that establish the bases to be followed at lower levels. Subsequently, it focuses on its national or internal development, and for this, it begins by analyzing the Spanish regulations and continues with the observation of the autonomic ones. After six years since Law 45/2015, of October 14, on volunteering came to light, its regulatory development is still pending approval. Although progress has been made in the Royal Decree project, improvements could be made before publication. To this end, its content has been analyzed, and proposals for modifications are made that would bring the regulation closer to international organizations' indications to differentiate traditional from corporate or company volunteering. On the other hand, given the diversity of regulations in the diverse autonomous communities, it is considered interesting to examine their degree of uniformity and whether they have improved or restricted state legislation. The purpose of this comparison is to contrast possible divergences in the various regulatory frameworks. To present a complete study on the different actions, the different plans or strategies of corporate volunteering developed in the Spanish state and autonomous region will be shown, and the presentation of volunteering in them.

Keywords: Employees volunteering; Corporate volunteering; Volunteer strategies; Employees; Autonomous regions.

Sumario. 1. Introducción. 2. El voluntariado en el ámbito internacional. 3. Marco normativo del voluntariado en España. 4. Los planes estratégicos de voluntariado en España. 5. Conclusiones. 6. Referencias bibliográficas.

Cómo citar. Lor Serrano, A.; Esteban Salvador, L. (2021) Análisis del marco jurídico del voluntariado de empresa en España. REVESCO. Revista de Estudios Cooperativos, vol. 139, e78537. https://dx.doi.org/10.5209/reve.78537.

1 Este estudio se ha realizado con el apoyo económico del Gobierno de Aragón (Grupo de Investigación CEMBE-proyecto S11_20R) cofinanciado con FEDER 2014-2020 “Construyendo Europa desde Aragón”, y de la Fundación Universitaria Antonio Gargallo (2020/B013).

2 Universidad de Zaragoza, España.

Dirección de correo electrónico: 513953@unizar.es

3 Universidad de Zaragoza, España.

Dirección de correo electrónico: 1uisaes@unizar.es. 


\section{Introducción}

Delimitar el concepto de voluntariado de empresa, voluntariado corporativo, voluntariado organizacional, o voluntariado de trabajadores y trabajadoras es complicado por la inexistencia de una única definición. El abanico de términos se amplía cuando recogemos sus muchas variedades en lengua inglesa, entre las que destacan términos como corporate volunteering, corporate volunteerism, employee volunteerism, employee volunteering, employee community involvement, employer-supported volunteering, o workplace voluntarism. El voluntariado de empresa constituye la vía con la que las corporaciones demuestran que son socialmente responsables y generan capital social, buscando construir redes, elementos de confianza y cooperación entre el personal empleado, las empresas y las organizaciones comunitarias (Cosenza et al., 2018; Habisch et al., 2001; Moon, 2001; Muthuri et al., 2006; Sajardo Moreno \& Ribas Bonet, 2014).

Existen numerosas definiciones de voluntariado de empresas, entre ellas la de la Fundación Adecco que se refiere a este como "El conjunto de actividades promovidas y apoyadas por una empresa que tienen como finalidad la involucración y participación libre de sus empleados a través de la dedicación de su tiempo, capacidades y talento a causas, proyectos y organizaciones sin ánimo de lucro" (Fundación Adecco, 2011). Por su parte, Business in The Community (BITC) lo concibe como "La movilización de las empresas, en tiempo, talento, energía y recursos de sus empleados para contribuir a la comunidad. Esto incluye: compromiso a largo plazo, desarrollo de capacidades y tareas concretas, transferencias de capacidades, desafíos de trabajo en equipo, y apoyo de la compañía a los proyectos" (Recogido en Sajardo Moreno \& Ribas Bonet, 2014:166; Saz Gil \& Zardoya Alegría, 2014: 84). Mientras que Paloma Lemonche subraya el cometido socialmente responsable de entidades públicas y privadas dirigido a la comunidad, dentro de sus estrategias de gestión. Para la mencionada autora, en los programas de voluntariado de empresa, el personal empleado protagoniza los proyectos y conforma el compromiso de su entidad con la sociedad, mientras que el papel de la empresa se centra en decidir, organizar, planear, destinar recursos, supervisar, comunicar resultados e integrar los proyectos en su estrategia "de acción social". De hecho, "en la práctica totalidad de los casos ambos actores coordinan sus esfuerzos con una organización no lucrativa, buena conocedora de la causa social elegida y de la forma más adecuada de llevar a cabo los proyectos, que canaliza los esfuerzos y recursos puestos en juego por la empresa en beneficios de la sociedad" (Lemonche, 2011:12).

El objetivo de este estudio es analizar los principales aspectos relativos a la regulación del voluntariado de empresas comenzando con el marco internacional, para continuar con el estado de la cuestión en la legislación estatal y seguir con el de las comunidades autónomas españolas. Este trabajo complementa a otros en los que se analiza el voluntariado de empresa desde el marco normativo, al incluir otras perspectivas como por ejemplo la problemática que puede causar, o los beneficios que proporciona a todas las partes implicadas.

El trabajo se estructura del siguiente modo. En la siguiente sección se analiza el marco internacional del voluntariado de empresas, emanado de diferentes instituciones internacionales. Posteriormente se abordan los aspectos relacionados con el voluntariado de empresa en el marco normativo estatal en España, a continuación, se analiza la legislación de las distintas comunidades autonómicas, y sus planes estratégicos, y para finalizar se presentan las conclusiones del estudio.

\section{El voluntariado en el ámbito internacional}

En el marco global son numerosas las resoluciones de la Organización de Naciones Unidas (ONU) sobre voluntariado, en especial destaca la Resolución 56/38 de 5 de diciembre de 2002 aprobada por la Asamblea General de Naciones Unidas, de Recomendaciones sobre el apoyo al voluntariado, que a través de su apartado 5 insta a los gobiernos a que establezcan las medidas para apoyar las actividades de voluntariado. En particular, al concretar la finalidad del voluntariado de empresas en su normativa, indica lo siguiente:

- Aprobación de leyes que actúen como incentivo. El objetivo es alentar o servir de inspiración a la ciudadanía para que preste servicios voluntarios, aunque la decisión queda en manos de la persona o la organización; también se pueden facilitar las actividades voluntarias de los empleados/as. Se pueden proporcionar incentivos fiscales y subvenciones para las organizaciones, así como cobertura y protección contra los riesgos, de manera acorde con la sociedad de que se trate;

- Facilitar el establecimiento de alianzas con motivo de las actividades de la sociedad civil basadas en el servicio voluntario, que pueden incluir mecanismos para la planificación, ejecución y supervisión conjuntas y la incorporación de las actividades voluntarias de los empleados del sector privado.

Por otro lado, cabe subrayar que en el ámbito empresarial, esta institución considera que "una estimación más precisa de los beneficios del voluntariado para las destrezas y el bienestar de las personas trabajadoras 
podría dar pie a una mejora cuantitativa y cualitativa de los programas de voluntariado existentes" (ONU, 2015), además, la mencionada institución indica que con ello se daría impulso a la eficiencia empresarial.

Otro de los organismos que vela por el trabajo voluntario es la Organización Internacional del Trabajo (OIT). Esta entidad considera que algunas empresas fomentan la participación de su personal empleado en programas de voluntariado corporativo a través de incentivos como por ejemplo de vacaciones pagadas, indicando que cuando se da este tipo de estímulos "la actividad resultante no respeta la disposición de "no remunerado' de la definición recomendada y, en consecuencia, no debería ser contabilizada como trabajo voluntario. Más bien debería considerarse como una contribución en especie de parte de la empresa" (OIT, 2011). Por otro lado, la OIT entiende que cuando no exista compensación financiera se considerará trabajo voluntario.

A estas referencias internacionales, deberíamos añadir, para completar el marco legislativo internacional del voluntariado de empresas, las distintas menciones emanadas de la normativa de la Unión Europea, en las que se contempla el voluntariado corporativo. Esta institución, a través del apartado 11 de la Resolución del Parlamento Europeo, de 22 de abril de 2008, sobre la función del voluntariado como contribución a la cohesión económica y social (2007/2149(INI) $)^{4}$ anima a organizaciones y empresas del sector privado a respaldar financieramente el voluntariado dentro de su estrategia de responsabilidad social. Desde la Unión Europea, se trata de impulsar el voluntariado corporativo, recomendando a las distintas empresas o compañías y al Estado a que incentiven este tipo de prácticas mediante el apoyo financiero y logístico. Además, la Comunicación sobre políticas de la UE y voluntariado: Reconocimiento y fomento de actividades voluntarias transfronterizas en la $\mathrm{UE}^{5}$ indica en su apartado 2.2.6, que: "El voluntariado entre los trabajadores como expresión de responsabilidad social de las empresas, tanto el sector público como el privado desempeñan un papel importante en el fomento de actividades voluntarias. Al invertir en el voluntariado entre los trabajadores, no solo hacen un bien a la comunidad local, sino que al mismo tiempo mejoran su imagen y su reputación, ayudan a crear espíritu de equipo, mejoran la satisfacción en el trabajo y aumentan la productividad, a la vez que permiten a los trabajadores o funcionarios desarrollar nuevas capacidades".

Con el fin de promover el voluntariado entre su plantilla, en 2011 la Comisión puso en marcha iniciativas que pretenden fomentar el voluntariado entre sus trabajadores y trabajadoras, como recursos web en intranet para su personal, en los que se publica información para desarrollar actividades de voluntariado ${ }^{6}$, lo que significa que la propia Comisión apoya la implantación de este tipo de actividades en su seno, acompañándola de una serie de ejemplos ${ }^{7}$ además de redirigir en la propia norma a su portal de voluntariado. No obstante, al tratarse de un portal de voluntariado interno, algunos de esos recursos no se pueden analizar dado que no son accesibles para toda la ciudadanía.

Esta institución se refiere al "voluntariado entre los trabajadores", e incide en la importancia del sector público y del privado, en su fomento. El Comité Económico y Social Europeo (CESE) considera que debe estudiarse en profundidad la participación de entidades empresariales que cuentan con experiencias de voluntariado corporativo u otras, y valora el papel de las pequeñas y medianas empresas. Para el CESE debería aumentarse la sensibilización sobre las distintas maneras en que el sector empresarial podría apoyar las actividades individuales de voluntariado de trabajadores y trabajadoras, como manifestación de sus programas de responsabilidad social. Además, para este organismo, los interlocutores sociales deberían tener voz en los distintos programas de voluntariado de los recursos humanos, apoyados en el principio del carácter voluntario de la participación de estos últimos. Respecto a la involucración de entidades empresariales que también cuentan con experiencias de voluntariado corporativo u otras, el CESE cree que es un tema que debe estudiarse en profundidad a fin de proponer algunos mecanismos para esta participación. En cualquier caso, para el CESE es importante el impulso a las pequeñas y medianas empresas y no solo, como en ocasiones ha sucedido, a las grandes corporaciones que cuentan con departamentos de RSC (responsabilidad social corporativa) o similares ${ }^{8}$.

Por otro lado, la Comisión Europea publicó un estudio sobre el Voluntariado de Empleados en Europa ${ }^{9}$ en 2014, elaborado por fundación Codespa y por el CEV (European Volunteer Centre), cuyo objetivo era

En https://eur-lex.europa.eu/legal-content/ES/TXT/PDF/?uri=CELEX:52008IP0131\&rid=1 (Consultado el 2 de marzo de 2021).

De la Comisión al Parlamento Europeo, al Consejo, al Comité Económico y Social Europeo y al Comité de las Regiones, de 20.9.2011disponible en: https://ec.europa.eu/transparency/regdoc/rep/1/2011/ES/1-2011-568-ES-F1-1.pdf (Consultado el 20 de febrero de 2021).

6 Véase: http://myintracomm.ec.europa.eu/serv/en/Volunteering/ También hay que mencionar que el personal de la Comisión organiza y dirige iniciativas de caridad como el Schuman Trophy, la campaña «Shoe box for the homeless», el grupo de apoyo al cáncer, la delegación de la UE ATD Quart Monde o la asociación GIVE EUR-HOPE, creada recientemente.

7 Entre ellos cabe citar el Dictamen del Comité Económico y Social Europeo sobre el tema "El Cuerpo Voluntario Europeo de Ayuda Humanitaria: posibilitar e impulsar la incorporación de ciudadanos de todos los Estados miembros de la Unión" (Dictamen exploratorio solicitado por la Presidencia lituana) (2014/C 67/03).

8 Por ejemplo, el CESE organizó conjuntamente varios actos: 2 a Conferencia Temática a nivel de la UE (23-24 de mayo), organizada por la Comisión Europea. En el CESE se celebraron los debates relacionados sobre todo con el voluntariado de los trabajadores y trabajadoras.

9 Employee Volunteeting and Employee Volunteering in Humanitarian aid in Europe, June 2014 Disponible en: https://ec.europa.eu/echo/files/euaidvolunteers/EUAV_Study_Employee Volunteering_Europe FINAL en.pdf (consultado el 20 de febrero de 2021). 
conocer la situación del VE en Europa, para preparar el programa de voluntariado de la $\mathrm{UE}^{10}$. De este trabajo se desprende que una de las principales barreras para el desarrollo de este tipo de iniciativas es el desconocimiento de cómo los empleadores/as podrían gestionar estos esquemas o participar en este tipo de proyectos. Otra de las iniciativas de la Unión Europea para fomentar el voluntariado es el Servicio de Voluntariado Europeo $(\mathrm{SVE})^{11}$, que se trata de un programa que financia la Comisión Europea para que los y las jóvenes con residencia europea puedan participar como voluntarios/as en organizaciones de distintos continentes. Además, el Centre for European Volunteering ${ }^{12}$, hasta julio de 2020 conocido como European Volunteer Centre, apoya el voluntariado en Europa en los ámbitos nacional y regional.

\section{Marco normativo del voluntariado en España}

\section{1. Ámbito estatal}

El voluntariado es una actividad revestida de gran valor y significado, que puede llegar, en su mejor forma, a influir en el modo en que el poder se distribuye en la sociedad (Allen, 2011). En España la Plataforma del Voluntariado de España (PVE) o el Observatorio del Voluntariado son ejemplos de iniciativas puestas en marcha. Con carácter previo a la vigente normativa, tuvieron lugar cuatro Planes Estatales de Voluntariado, entre los años 1997 y $2014^{13}$, el primero, un año posterior a la primera ley y el último, el año anterior a la aprobación de la actual legislación. Sin embargo, para poder entenderse la normativa es preciso diferenciar entre el voluntariado tradicional y el voluntariado empresarial. El voluntariado tradicional cuenta, desde 1996, con su propio marco normativo, contenido en la Ley 6/1996, de 15 de enero, del Voluntariado, modificada por la Ley 45/2015, de 14 de octubre, de Voluntariado. A través del artículo 3, se define el concepto legal de voluntariado tradicional como "El conjunto de actividades de interés general desarrolladas por personas físicas, siempre que reúnan los siguientes requisitos: a) Que tengan carácter solidario. b) Que su realización sea libre, sin que tengan su causa en una obligación personal o deber jurídico y sea asumida voluntariamente. c) Que se lleven a cabo sin contraprestación económica o material, sin perjuicio del abono de los gastos reembolsables que el desempeño de la acción voluntaria ocasione a los voluntarios de acuerdo con lo establecido en el artículo 12.2.d). d) Que se desarrollen a través de entidades de voluntariado con arreglo a programas concretos y dentro o fuera del territorio español sin perjuicio de lo dispuesto en los artículos 21 y 22".

Además, el apartado segundo aclara qué se entiende por actividades de interés general, y serían "aquellas que contribuyan en cada uno de los ámbitos de actuación del voluntariado a que hace referencia el artículo 6 a mejorar la calidad de vida de las personas y de la sociedad en general y a proteger y conservar el entorno". Esta definición permite determinar que el voluntariado de empresas podría integrarse dentro del concepto legal de voluntariado tradicional. En otras palabras, podría constituir un subtipo más del mismo, pues ambos deben ser solidarios, voluntarios y sin contraprestación económica. En el preámbulo de la Ley 45/2015, de 14 de octubre se aclara que el voluntariado además de impulsarse en el Tercer Sector debería abarcar esferas más novedosas como la empresarial, la universitaria o la de las administraciones públicas.

Del análisis de la normativa se observa que, aunque en el desarrollo reglamentario se hace referencia a las pequeñas y medianas empresas, se dejan de lado en la propia Ley, a excepción de esta mención. Además, no se hace alusión a las grandes corporaciones, como se puede observar en el artículo 6 en el que se especifican distintos tipos de voluntariado como el social, el ambiental, el deportivo, el educativo, o el socio-sanitario, entre otros, sin hacer mención expresa al voluntariado empresarial.

No obstante, al analizar pormenorizadamente el contenido de la norma, encontramos referencias indirectas a la variante de voluntariado de empresa, en los artículos 9.1, 20.2 y 21, cuyo contenido se recoge, a continuación. Así en el artículo 9.1, se determina: "Los trabajadores por cuenta ajena y los empleados públicos, sólo podrán realizar actividades de voluntariado fuera de la jornada laboral, sin perjuicio de lo establecido en el apartado 2 del artículo 20". El mencionado artículo 20.2 enuncia lo siguiente: "Las Administraciones públicas y las empresas o instituciones privadas podrán promover y facilitar, de acuerdo con la legislación laboral o de empleo público y con pleno respeto a lo acordado en la negociación colectiva, la adopción de medidas de reducción o adaptación de la jornada laboral, suspensiones de la relación laboral con reserva de puesto de trabajo o interrupciones de la prestación retribuidas o no, para

10 Los métodos utilizados han incluido una revisión de la literatura, encuestas, entrevistas, grupos focales y visitas de campo. En su desarrollo participaron más de 280 stakeholders de diferentes grupos de interés tanto: Sector humanitario (ONG, agencias, etc.), empresarias y empresarios tanto del sector público como del privado, empleadas y empleados de ambos sectores y expertas y expertos internacionales. Se destaca que se realizó una encuesta online y se recibieron 203 respuestas de todos los países de la UE. España fue el país que más aportó a la muestra con un $13 \%$ del total de las mismas.

11 En https://serviciovoluntarioeuropeo.org/que-es-sve/ (consultado el 21 de febrero de 2021).

12 Véase https://www.europeanvolunteercentre.org/ (consultado el 21 de febrero de 2021).

13 Véase en https://www.mscbs.gob.es/ssi/familiasInfancia/ongVoluntariado/voluntariadoEstrategia.htm (consultado el 21 de febrero de 2021). 
que los trabajadores por cuenta ajena o empleados públicos, puedan ejercer sus labores de voluntariado. Los términos concretos en que se vayan a desarrollar las medidas de reducción o adaptación de la jornada laboral, mencionadas en el anterior párrafo deberán constar por escrito".

Cabe señalar que el texto legal dedica el artículo 21, a la promoción del voluntariado de empresas, y reconoce su fomento empresarial en los siguientes términos: "1. Con el fin de fomentar una mayor visibilidad e impulso del voluntariado en la sociedad, las empresas podrán promover y participar en programas de voluntariado siempre que las actuaciones que realicen puedan calificarse como de interés general, se incluyan en alguno de los ámbitos de actuación de voluntariado y respeten los valores y principios que inspiran la acción voluntaria, de acuerdo con lo establecido en el Título I. 2. Las actuaciones de voluntariado de las empresas podrán llevarse a cabo mediante la incorporación de los trabajadores que decidan participar libre y voluntariamente como voluntarios en programas promovidos por entidades de voluntariado en colaboración con la empresa".

La normativa española sobre voluntariado dispone a través de su artículo 21.3 que "reglamentariamente se establecerán las especialidades pertinentes a efectos de fomentar y facilitar que las Pymes promuevan y participen en programas de voluntariado". A fecha de hoy no ha sido aprobado el reglamento, si bien existe el proyecto de Real Decreto por el que se aprobaría el reglamento de ejecución de la ley 45/2015, de 14 de octubre de voluntariado, documento que fue sometido a consulta pública previa a su aprobación, según lo establecido por el artículo 133 de la ley 39/2015, de 1 de octubre, del Procedimiento Administrativo Común, en junio de $2017^{14}$. Cabe destacar que en el proyecto se indica que el 7 de noviembre de 2017 se solicitó informe al Consejo Estatal de organizaciones no gubernamentales de Acción Social, a la Comisión para el Diálogo Civil con la Plataforma del Tercer Sector y a la Secretaría General Técnica del Departamento, sin embargo, no tenemos constancia de ninguno de estos informes, o del que debería emitir el Consejo de Estado, por tratarse de un reglamento de desarrollo de una Ley. En dicho proyecto, se indicaba que el reglamento debería ser elaborado con la colaboración de entidades como la Plataforma del Voluntariado de España, o Forética, a las que consideran entidades expertas en el voluntariado de empresas y en responsabilidad social corporativa.

Dentro del cuerpo legal de este reglamento se incluyen los títulos X y XI dedicados a la acción voluntaria, que promocionaría el voluntariado desde las empresas, las universidades y las Administraciones Públicas, a la vez que instauraría modelos de certificación de las competencias adquiridas por las personas voluntarias durante su vida.

Si bien, destaca, que el proyecto de reglamento contenga una sección ${ }^{15}$ dedicada a la participación de las empresas en programas de voluntariado. En ella, el artículo 68, siguiendo el mandato del artículo 21 de la Ley de voluntariado, expone que las empresas deberán colaborar en programas de voluntariado que ellas mismas impulsen, o en otros compartidos con las entidades de voluntariado, para lo que se exigirán acuerdos de colaboración entre ambas instituciones, que contengan, al menos, entre otros, la denominación del programa, los ámbitos y condiciones de las personas trabajadoras, la formación que deberá recibir el personal de la empresa, y el plazo de duración y renovación, entre otros.

Además, el propio proyecto establece que no se podrá producir menoscabo de los derechos de los trabajadores ante la negativa de los mismos a participar de este tipo de programas. No obstante, no sólo abarcaría al personal de la plantilla actual de la empresa, sino que, dentro del ámbito del impulso del voluntariado entre mayores de sesenta años, como medio de envejecimiento activo, se contempla la participación de las personas jubiladas, prejubiladas y sus familias.

También es interesante que desde el propio proyecto se recoja la necesidad de potenciar la participación de las Pymes en programas de voluntariado de empresas. Se llegará a potenciar la participación de las empresas y universidades incluso a través de Comisiones en el Observatorio Estatal de voluntariado, buscando la máxima cooperación entre estas y las entidades de voluntariado.

Sin embargo, la colaboración creciente entre las entidades de voluntariado y las empresas ha causado cierta incertidumbre (Benlloch Sanz, 2017), y a pesar de la libertad de los trabajadores y trabajadoras para implicarse en actividades de voluntariado, podría darse el caso de que se realice "bajo presión de la empresa o de los pares, que tengan expectativas falsas de recibir algún tipo de compensación o ascenso y que haya retraso en las tareas en la medida que se dedique tiempo a las actividades de voluntariado" (Cuevas-Torres et al., 2015, p. 266). Baviera (2014) va más allá al plantear la posibilidad de que bajo el paraguas del voluntariado se lleven a cabo "relaciones laborales encubiertas". La autora tras realizar un análisis de la jurisprudencia española indica que este fenómeno no es "una cuestión pacífica, pues se encuentra repleto de 'zonas grises', donde la línea divisoria entre una relación laboral o de voluntariado no siempre resulta precisa" (Baviera, 2014). Además, el voluntariado podría verse como una manera de conseguir mano de obra barata por el empresariado (Martínez Ripoll, 2017).

14 En https://www.mscbs.gob.es/normativa/docs/CONSULTAVOLUNTARIADO.pdf (consultado el 6 de marzo de 2021).

15 En la Sección I, del título X. Del fomento y reconocimiento de la acción voluntaria. 
El beneficio integral del voluntariado ha sido definido por algunos autores y autoras como una situación de win-win (Allen, 1989; Points of Light Foundation, 2007), o, win, win, win (Benjamin, 2001; Bowen et al., 2009; Caligiuri et al., 2013; Peloza \& Hassay, 2006; Valor Martínez, 2002), o incluso de win-win-win-winwin (Graff, 2004). Lo que implicaría que no sólo ganan los voluntarios/as y aquellos/as que reciben el voluntariado, o las personas que practican el voluntariado, o las que lo reciben, sino la sociedad en general, es decir, si seguimos a (Graff, 2004), se beneficiarían de esta situación la comunidad, las ciudadanas y los ciudadanos individuales, los gobiernos, las empresas y el personal empleado que participa de este tipo de prácticas. Así, algunos estudios subrayan los resultados positivos del voluntariado, por ejemplo, en un análisis realizado en Andalucía se concluyó que el voluntariado corporativo incrementa la satisfacción laboral y el compromiso del personal empleado, lo que lleva a las empresas a obtener una ventaja competitiva mediante las actividades de voluntariado sin que ello suponga grandes inversiones presupuestarias para la entidad (Ruizalba et al., 2014).

\section{2. Ámbito autonómico}

Con el fin de delimitar el marco normativo del voluntariado en las distintas comunidades autónomas, y poder compararlo, tanto entre ellas como con la normativa estatal, hemos recopilado la legislación en la Tabla 1. Como puede apreciarse tan solo las comunidades autónomas de Andalucía, Aragón e Islas Baleares cuentan con una ley de voluntariado posterior a la estatal. Por otro lado, se omiten en el listado las ciudades autónomas de Ceuta y Melilla por carecer de legislación propia sobre voluntariado, en su caso habrá que remitirse a la normativa estatal.

Tabla. 1. Legislación sobre Voluntariado de las Comunidades Autónomas

\begin{tabular}{|c|c|}
\hline Andalucía & $\begin{array}{l}\text { Ley } 4 / 2018 \text {, de } 8 \text { de mayo, Andaluza del Voluntariado. } \\
\text { Decreto } 123 / 2003 \text {, de } 6 \text { de mayo, por el que se aprueba el I Plan Andaluz del } \\
\text { Voluntariado en Andalucía. }\end{array}$ \\
\hline Aragón & Ley 6/2018, de 28 de junio, del Voluntariado de Aragón. \\
\hline Asturias & $\begin{array}{l}\text { Ley del Principado de Asturias 6/2019, de } 29 \text { de marzo, de Participación y } \\
\text { Promoción Juvenil. } \\
\text { Ley del Principado de Asturias 10/2001, de } 12 \text { de noviembre, del Voluntariado. }\end{array}$ \\
\hline Canarias & Ley 4/1998, de 15 de mayo, de Voluntariado de Canarias. \\
\hline Cantabria & $\begin{array}{l}\text { Decreto 59/2000, de } 26 \text { de julio, por el que se regula el Voluntariado Cultural en } \\
\text { Cantabria. } \\
\text { Decreto } 1 / 2019 \text {, de } 17 \text { de enero, por el que se regulan las organizaciones de } \\
\text { voluntariado de Protección Civil de Cantabria y el Registro de Organizaciones de } \\
\text { Voluntariado de Protección Civil. - Boletín Oficial de Cantabria de } 25 \text { de enero de } \\
2019 \text {. }\end{array}$ \\
\hline Castilla la Mancha & Ley 4/1995, de 16 de marzo, de Voluntariado en Castilla-La Mancha. \\
\hline Castilla-León & $\begin{array}{l}\text { Ley } 8 / 2006 \text {, de } 10 \text { de octubre, del Voluntariado en Castilla y León. } \\
\text { Decreto 53/2003, de } 30 \text { de abril, por el que se crea la Comisión Regional de } \\
\text { Voluntariado de Castilla y León. }\end{array}$ \\
\hline Cataluña & Ley $25 / 2015$, de 30 de julio, del Voluntariado y de Fomento del Asociacionismo. \\
\hline Comunidad Valenciana & Ley 4/2001, de 19 de junio, del Voluntariado. \\
\hline Extremadura & Ley 1/1998, de 5 de febrero, reguladora del Voluntariado Social en Extremadura. \\
\hline Galicia & Ley 10/2011, de 28 de noviembre, de Acción Voluntaria. \\
\hline Islas Baleares & Ley 11/2019, de 8 de marzo, de Voluntariado de las Illes Balears. \\
\hline La Rioja & Ley $7 / 1998$, de 6 de mayo, del Voluntariado. \\
\hline Madrid & Ley $1 / 2015$, de 24 de febrero, del Voluntariado en la Comunidad de Madrid. \\
\hline Murcia & Ley 5/2004, de 22 de octubre, del Voluntariado en la Región de Murcia. \\
\hline Navarra & Ley Foral 2/1998, de 27 de marzo, del Voluntariado. \\
\hline País Vasco & $\begin{array}{l}\text { Ley } 17 / 1998 \text { de } 25 \text { de junio } 1998 \text {, del Voluntariado. } \\
\text { Decreto } 30 / 2003 \text {, de } 18 \text { de febrero, de funcionamiento del Consejo Vasco del } \\
\text { Voluntariado. }\end{array}$ \\
\hline
\end{tabular}

Fuente: Elaboración Propia 
A continuación, se presentan las referencias al voluntariado de empresas que hacen cada una de las diecisiete Comunidades Autónomas en España dentro de su normativa específica. Si bien, se van a articular en dos ejes, aquellas que sí contemplan el voluntariado de empresas, aunque sea de forma implícita, y las que, por el contrario, no contemplan este tipo de práctica. Entre las comunidades autónomas que, a pesar de contar con normativa sobre voluntariado no contemplan el VE encontramos a: la Comunidad Autónoma del Principado de Asturias ${ }^{16}$, a la Comunidad Autónoma de Cantabria ${ }^{17}$, a la Comunidad Autónoma de Castilla La Mancha $^{18}$, a la Comunidad Autónoma de Castilla León ${ }^{19}$, a la Comunidad Autónoma de Valencia ${ }^{20}$, a la Comunidad Autónoma de Extremadura ${ }^{21}$, a la Comunidad Autónoma de La Rioja ${ }^{22}$, a la Comunidad Autónoma de la Región de Murcia ${ }^{23}$, a la Comunidad Foral de Navarra ${ }^{24}$, y a la Comunidad Autónoma del País Vasco ${ }^{25}$.

Seguidamente, enumeramos a aquellas comunidades que sí contemplan el voluntariado, a la vez que se analiza el contenido más destacado de esta normativa, en el ámbito de referencia de este estudio.

Comunidad Autónoma de Andalucía. En la exposición de motivos de la Ley 4/2018, de 8 de mayo, Andaluza del Voluntariado se incluye a las empresas y universidades como agentes para el desarrollo del voluntariado. Además, a través de su artículo tercero, apartado 3.f se excluyen como actividades de voluntariado las prácticas externas académicas y las que no sean laborales que se desarrollen en organizaciones empresariales incluidos sus grupos. Por medio de su artículo 27.1 indica que se llevará a cabo el fomento del voluntariado por diversas instituciones públicas y privadas -concretamente menciona a administraciones públicas, empresas, universidades e instituciones privadas-, y se facilitará que las personas se incorporen al voluntariado "sin desvirtuar el carácter gratuito del voluntariado y garantizando que no suponga la cobertura de un puesto de trabajo, servicio o programa que sea necesario desarrollar de manera profesional". Además, en el apartado 2 del mismo artículo 27, se señala que, para que el personal pueda ejercer labores de voluntariado, las mencionadas entidades, de acuerdo con la normativa laboral o de empleo público, según el caso, y respetando la negociación colectiva, podrán promover o facilitar que se adopten medidas que disminuyan o adapten la jornada de trabajo, o que se suspenda la relación laboral "con reserva de puesto de trabajo o interrupciones de la prestación retribuidas o no".

Asimismo, la legislación andaluza dedica un artículo específico a la promoción del voluntariado desde las empresas en el que hace referencia a la negociación colectiva para su desarrollo, concretamente el 28. En el mismo se dispone que los mecanismos para facilitar al personal la compatibilización y conciliación de sus obligaciones laborales se podrá regular y especificar a través de la negociación colectiva. Además, las empresas, siempre y cuando, lleven a cabo sus actuaciones mediante entidades de voluntariado a través de un acuerdo de colaboración, sean de interés general, se enmarquen en alguno de los ámbitos de actuación del voluntariado, y respeten los principios y valores inspiradores de la acción voluntaria, podrán promover programas de voluntariado. Todo ello se realizará según lo recogido en el título I.3, que indica que las empresas respetarán que las personas que se impliquen en actividades de voluntariado lo hagan de manera libre y voluntaria, "en programas promovidos por entidades de voluntariado en colaboración con la empresa" Para ello será necesario que formalicen un acuerdo con la organización a la que se incorporen y que cumplan todos aquellos requerimientos y reglas de la entidad de voluntariado.

Finalmente, y en los mismos términos que la normativa estatal, dispone que se desarrollará reglamentariamente para que las PYMES participen y promuevan programas de voluntariado.

Comunidad Autónoma de Aragón. Las mismas carencias en relación con el reconocimiento expreso del voluntariado de empresas de la legislación nacional, se detectan en la norma autonómica aragonesa sobre voluntariado a través de La Ley 6/2018, de 28 de junio, del Voluntariado de Aragón. Y aunque, incide en esta categorización, lo hace de forma implícita, sin utilizar su denominación. Así, en su artículo 37.4, define cómo promocionar esta actividad en las empresas, y dispone que las actividades se realicen a través de entidades con voluntariado, y se suscriba un acuerdo que incluya "las líneas de actuación y el marco de la estrategia de responsabilidad social corporativa de la empresa que corresponda".

Del análisis de la Comunidad Autónoma aragonesa resulta innovadora la obligación de las empresas de proteger a sus trabajadores y trabajadoras a través de una póliza o seguro, para que los salvaguarde de cualquier contratiempo que se pudiera surgir en el desarrollo de la actividad de VE, ya sea accidente, enfermedad, o incluso de cobertura por responsabilidad civil (obligación contemplada por el 37.5).

\footnotetext{
Ley del Principado de Asturias 10/2001, de 12 de noviembre, del voluntariado es previa a la actual normativa estatal.

17 La normativa cántabra, aunque sí que contiene dos decretos, uno que hace referencia al voluntariado cultural y otro al voluntariado de protección civil no cuenta con una normativa de voluntariado.

Ley 4/1995, de 16 de marzo, de voluntariado en Castilla-La Mancha.

Ley 8/2006, de 10 de octubre, del voluntariado en Castilla y León.

Ley 4/2001, de 19 de junio, del voluntariado.

Ley 1/1998, de 5 de febrero, reguladora del voluntariado social en Extremadura.

Ley $7 / 1998$, de 6 de mayo, del voluntariado.

Ley 5/2004, de 22 de octubre, del voluntariado en la Región de Murcia.

La Ley Foral 2/1998, de 27 de marzo, del voluntariado.

La Ley 17/1998 de 25 de junio de 1998, del voluntariado no hace alusión al voluntariado de empresa.
} 
Por último, cabe señalar la búsqueda de colaboración en las entidades educativas para el desarrollo del voluntariado, especialmente, en los ámbitos formativo y de investigación. Así el artículo 38.4 de la normativa aragonesa insta a las universidades a que fomenten el voluntariado desde la docencia y la investigación, a través de convenios de colaboración con entidades públicas y privadas, las cuales " $a$ su vez podrán solicitar a la universidad cursos, estudios, análisis e investigaciones".

Comunidad Autónoma de Canarias. Ley 4/1998, de 15 de mayo, de Voluntariado de Canarias hace una única mención al ámbito empresarial a través de su Disposición adicional segunda, en la que hace referencia a la participación del personal al servicio de la Administración de la Comunidad Autónoma de Canarias o de sus organismos autónomos y empresas dependientes en actividades de solidaridad, sensibilización, educación y cooperación encaminadas al desarrollo a través de convenios de colaboración.

Comunidad Autónoma de Cataluña. La Ley 25/2015, de 30 de julio, del voluntariado y de fomento del asociacionismo, contempla una única referencia a las empresas en su artículo 18.8.e relativa a la composición del Consejo del Asociacionismo y el Voluntariado de Cataluña que estará integrado, entre otras personas, por dos organizaciones empresariales que tengan la consideración de más representativas en Cataluña en el ámbito de los servicios sociales, una en representación de las entidades de iniciativa social y otra en representación de las entidades de iniciativa mercantil que llevan a cabo acciones voluntarias desde la empresa.

Comunidad Autónoma de Galicia. La Ley 10/2011, de 28 de noviembre, de acción voluntaria, a través de su artículo 27 relativo al fomento de la acción voluntaria corporativa hace referencia a la promoción de este tipo de acción, que define como la que se lleva a cabo por "empresas en el entorno económico y social de su actividad mediante la adscripción de las trabajadoras y trabajadores de las mismas que, de modo totalmente libre, desinteresado, altruista y solidario, decidan contribuir a la realización de programas o proyectos de acción voluntaria promovidos por dichas empresas a través de entidades de acción voluntaria preexistentes o de nueva creación".

Además, en la composición del Consejo Gallego de Acción Voluntaria contará con tres vocalías en representación de las organizaciones empresariales.

Comunidad Autónoma de las Islas Baleares. La Ley 11/2019, de 8 de marzo, de voluntariado de las Illes Balears reconoce el papel de las universidades y de las empresas indicando que sus funciones son las de colaborar y promover el voluntariado desde sus ámbitos. Dedica el artículo 21 a las empresas, en el que indica que con el propósito de que en el seno de la sociedad se fomente e impulse el voluntariado, las empresas podrán participar y promover programas de voluntariado, siempre y cuando se lleven a cabo a través de la colaboración con una organización de voluntariado. Y para el fomento del voluntariado entre su personal, tanto empresas como administraciones podrán "adoptar acuerdos en el marco de la negociación colectiva que faciliten el acceso a los programas de voluntariado de las entidades".

Comunidad Autónoma de Madrid. En la Ley 1/2015, de 24 de febrero, del Voluntariado en la Comunidad de Madrid, se introduce en el Capítulo VI, sobre formas de voluntariado de consideración especial, un artículo, el 19, dedicado a la responsabilidad social empresarial y voluntariado corporativo. Define el voluntariado corporativo como "aquel promovido por una empresa o institución para que personas vinculadas a esta, (empleados, jubilados, accionistas, proveedores, entre otros), participen en actividades de voluntariado". Además, con el fin de que la sociedad madrileña se implique en las actividades de voluntariado, la Comunidad impulsará la responsabilidad social de las empresas a través del fomento de iniciativas. Y para ello "promoverá las acciones de voluntariado corporativo de las empresas con el objetivo de poner su experiencia y solidaridad al servicio de la sociedad. Asimismo, cuando estas se lleven a cabo "en colaboración con organizaciones de voluntariado, se suscribirá un acuerdo entre la empresa y la organización de voluntariado, en el que se establezcan las líneas de actuación y el marco de la estrategia de responsabilidad social corporativa de la empresa que corresponda".

En esta normativa se indica que para su redacción se ha contado con las empresas para la realización de sugerencias, aportaciones y propuestas.

\section{Los planes estratégicos de voluntariado en España}

\subsection{Planes Estatales}

En la actualidad, y tras la publicación de la última normativa de ámbito nacional, la Ley 45/2015, de 14 de octubre, de Voluntariado, no existen estrategias estatales de voluntariado en vigor. La última de ellas vio la luz en diciembre de 2010, hasta ese momento, como indican Sanz et al. (2012), habían estado vigentes en nuestro país tres planes estatales del voluntariado consecutivos, durante los períodos 1997-2000, 2001-2004 y 2005-2009, desde la aprobación de la primera Ley del Voluntariado Española en 1996. Resulta interesante hacer un pequeño estudio de las propuestas que la última estrategia estatal de voluntariado 2010-2015, realizada para el VE, ya que además de tomar en consideración esta práctica en el ámbito de la empresa, 
llevaba a cabo propuestas para los distintos agentes implicados sobre cómo incentivarla y mejorarla. Dentro del apartado "la situación actual del voluntariado en España", se decía que "...hay que destacar que resulta imprescindible profundizar en las relaciones entre la empresa privada y las $E N L^{26}$, que puede contribuir, tanto a la mejora de la gestión de las entidades, como a orientar la política de Responsabilidad Social Corporativa de las empresas hacia la promoción del voluntariado entre sus empleados" (Ministerio de Sanidad Política Social e Igualdad, 2010).

Si bien, unas líneas más adelante, enfocaba esa participación al aspecto económico, "es importante que se promueva su independencia financiera, a través de políticas que promuevan el contacto entre ENL y empresas socialmente responsables que estén dispuestas a financiar programas de voluntariado" (Ministerio de Sanidad Política Social e Igualdad, 2010), cuando ya hemos comentado que las plantillas no sólo realizan aportaciones económicas, sino que comprometen su tiempo, conocimientos o habilidades, y dedicación en las actividades de VE (Grant, 2012).

Destaca, por un lado, que el Ministerio considerara cómo líneas estratégicas para la divulgación del VE la difusión de las actividades desarrolladas dentro del ámbito empresarial a través de la involucración de los medios de comunicación como parte de la política de responsabilidad social corporativa de las empresas del ámbito de la comunicación y, el "Reconocimiento y difusión de las iniciativas y buenas prácticas emprendidas desde el sector empresarial en materia de Responsabilidad Social de las Empresas, acción voluntaria y participación social" (Ministerio de Sanidad Política Social e Igualdad, 2010); y por otro, que se pretendiera ahondar en el conocimiento del voluntariado, adoptando entre otras medidas el fomento de estudios e investigaciones sobre "la importancia de voluntariado corporativo en el marco de la Responsabilidad Social de las Empresas" (Ministerio de Sanidad Política Social e Igualdad, 2010). A la vez, que se proponía la realización de campañas que tuvieran como objetivo promover la participación ciudadana, incluidas las entidades empresariales, o la realización de actuaciones formativas dirigidas a las personas empleadas en empresas privadas a fin de incentivar su participación en actuaciones de VE. Estas actuaciones se completarían con la promoción del intercambio de experiencias y conocimientos entre entidades sin fines lucrativos y empresas, para mejorar la gestión del VE que incentiven a las empresas a implantar planes o programas de VE que consoliden la participación voluntaria del personal empleado.

Garcia Nieto (2012) indica que, para garantizar la eficacia de los programas de VE, sería necesaria, la realización de un seguimiento y evaluación por parte de la empresa, para lo que esta autora, siguiendo a Lemonche (2011), considera fundamental el desarrollo de un plan de voluntariado corporativo o VE, desagregado o específico, que permitiera, entre otras cuestiones, promover la identificación de las trabajadoras y los trabajadores con la cultura de empresa propiciando la cohesión social interna de la entidad empresarial, o favorecerla motivación laboral.

Los planes estatales de voluntariado no han estado exentos de críticas. Por ejemplo, Aranguren Gonzalo (2001) consideró que este tipo de planes pretendían generar una política de voluntariado que chocaba frontalmente con las características del voluntariado social, y que en síntesis debían garantizarla participación de la ciudadanía en la experiencia de la acción colectiva. Además, de acuerdo con el autor, la actividad, se focalizará en el cambio social que se vincule con la mejora de las condiciones de los colectivos más desfavorecidos, al denunciar las injusticias y la vulneración de los derechos de los más débiles, especialmente, si esta situación surge de la mala gestión de las Administraciones Públicas, con la que se tenderán puentes, pero de la que no se permitirán manipulaciones.

\subsection{Planes autonómicos}

De la misma forma que sucede en el ámbito estatal resulta interesante analizar el contenido de los planes de voluntariado o de las estrategias de voluntariado de las distintas comunidades autónomas. En la Tabla 2 se recogen los distintos planes. En ellos se observa que algo más de la mitad de las Comunidades Autónomas cuentan con planes estratégicos. 
Tabla. 2. Planes estratégicos sobre Voluntariado de las Comunidades Autónomas

\begin{tabular}{|c|c|}
\hline Andalucía & $\begin{array}{l}\text { IV Plan andaluz del voluntariado 2017-2020. } \\
\text { https://www.juntadeandalucia.es/export/drupaljda/publicacion/17/10/121017 IV\%20Plan\% } \\
\text { 20Andaluz\%20del\%20Voluntariado\%202017-2020.pdf (consultado el } 2 \text { de marzo de 2021). }\end{array}$ \\
\hline Aragón & $\begin{array}{l}\text { Estrategia aragonesa de voluntariado. } \\
\text { http://aragonparticipa.aragon.es/sites/default/files/presentacion_estrategia_aragonesa_de_vol } \\
\text { untariado.pdf (consultado el } 2 \text { de marzo de 2021). }\end{array}$ \\
\hline Asturias & $\begin{array}{l}\text { Plan Estratégico de Voluntariado Social 2018-2020 para la zona noroccidental, o } \\
\text { I Plan Estratégico de Voluntariado Social del Área I, 2018-2020 }\end{array}$ \\
\hline Canarias & $\begin{array}{l}\text { Estrategia canaria de voluntariado 2013-2016 } \\
\text { https://www.gobiernodecanarias.org/cmsweb/export/sites/derechossociales/voluntariado/.co } \\
\text { ntent/PDF/Anexo_informe_estrategias_definitivas.pdf (consultado el } 2 \text { de marzo de 2021). }\end{array}$ \\
\hline Cantabria & No se ha podido localizar. \\
\hline $\begin{array}{l}\text { Castilla } \\
\text { Mancha }\end{array}$ & $\begin{array}{l}\text { Borrador, II Plan de Voluntariado de Castilla-La Mancha. } \\
\text { http://observatoritercersector.org/pdf/recerques/Plancastillalamancha.pdf (consultado el } 2 \text { de } \\
\text { marzo de 2021). }\end{array}$ \\
\hline Castilla-León & No se ha podido localizar. \\
\hline Cataluña & No se ha podido localizar. \\
\hline $\begin{array}{l}\text { Comunidad } \\
\text { Valenciana }\end{array}$ & $\begin{array}{l}\text { Plan estratégico del voluntariado de la Comunidad Valenciana y plan de acción del } \\
\text { voluntariado (2005-2008). } \\
\text { http://www.iniciativasocial.net/legis/plan_estrategico_vol_0508.pdf(consultado el } 2 \text { de } \\
\text { marzo de 2021). }\end{array}$ \\
\hline Extremadura & No se ha podido localizar. \\
\hline Galicia & $\begin{array}{l}\text { Plan de voluntariado para o Xacobeo } 2021 . \\
\text { https://voluntariadogalego.org/sites/default/files/2021- } \\
\text { 01/Plan_voluntariado_Xacobeo21_V3_compressed-2_DEF_1.pdf (consultado el } 2 \text { de marzo } \\
\text { de 2021). } \\
\text { Otros planes: } \\
\text { https://voluntariadogalego.org/es/planes-y-programas (consultado el } 2 \text { de marzo de 2021). }\end{array}$ \\
\hline Islas Baleares & No se ha podido localizar. \\
\hline La Rioja & https://www.larioja.org/medio-ambiente/es/agua/amigos-rios/programa-voluntariado ${ }^{28}$. \\
\hline Madrid & $\begin{array}{l}\text { Estrategia de voluntariado de la Comunidad de Madrid 2017-2021. } \\
\text { https://www.comunidad.madrid/transparencia/sites/default/files/plan/document/estrategia_d } \\
\text { e_voluntariado_2017-2021_0.pdf (consultado el } 2 \text { de marzo de 2021). }\end{array}$ \\
\hline Murcia & No se ha podido localizar. \\
\hline Navarra & $\begin{array}{l}\text { Plan de acción voluntariado 2018-2020. } \\
\text { https://solidaridadintergeneracional.es/files/biblioteca/documentos/plan_accion_voluntariad } \\
\text { o_2018-2020_navarra.pdf(consultado el } 2 \text { de marzo de 2021). } \\
\text { Estrategia Navarra de voluntariado. } \\
\text { http://www.navarra.es/NR/rdonlyres/C22143CC-B140-42E2-A9F5- } \\
\text { 62679594FEC4/303113/080115ps81.pdf (consultado el 4 de marzo de 2021). }\end{array}$ \\
\hline País Vasco & $\begin{array}{l}\text { Estrategia vasca del voluntariado 2017-2020. } \\
\text { https://www.euskadi.eus/informacion/estrategia-vasca-del-voluntariado-ano-2017- } \\
\text { 2020/web01-a2bolunt/es/ (consultado el } 2 \text { de marzo de 2021). } \\
\text { https://www.euskadi.eus/contenidos/informacion/estrategia_voluntariado_2017/es_def/adjun } \\
\text { tos/estrategiavascadelvoluntariado_es.pdf (consultado el } 2 \text { de marzo de 2021). }\end{array}$ \\
\hline
\end{tabular}

Fuente: Elaboración Propia

A continuación, exponemos las referencias que se realizan sobre el voluntariado de empresa en cada una de las estrategias o planes de voluntariado que se han podido localizar, respecto al resto, pensamos que no existen planes de voluntariado, dado que no ha sido posible suobtenciónen internet.

Comunidad Autónoma de Andalucía. Dentro de los objetivos del Plan Andaluz del Voluntariado 20172020, se hace mención a la innovación y más concretamente se indica que es preciso fomentar los sistemas de responsabilidad social empresarial en Andalucía. En el análisis de actuaciones previas, se considera qué se

27 Si bien se hace mención a este documento en varias páginas web, no se permite descargar el documento https://www.socialasturias.es/serviciossociales/voluntariado/el-principado-presentara-el-plan-estrategico-de-voluntariado-social-2018-2020-para-la-zonanoroccidental 1087293203601 in.html (consultado el 6 de marzo de 2021).

28 Aunque aparece el título, no se encuentra el documento en la página web. 
ha realizado y qué se quiere mantener. Entre todo lo hecho, aparecen los convenios de voluntariado con empresa, sindicatos y universidades, y entre las nuevas acciones que se proponen, se plantea impulsar la cultura de responsabilidad social de las empresas. Se programa la creación de un marco estratégico de promoción del voluntariado, conectándolo con líneas como RSC (a través del voluntariado corporativo).

Comunidad Autónoma de Aragón. En 2016, Aragón presentó a través de la Dirección General de Participación Ciudadana, Transparencia, Cooperación y Acción Exterior, el documento "Hacia la construcción de una estrategia aragonesa de voluntariado". En este documento, se prevé la creación de un espacio para asesorar a las empresas en la puesta en marcha del llamado voluntariado corporativo, o voluntariado promovido por las empresas, a través de organismos propios del Gobierno de Aragón, como el Instituto Aragonés de Fomento, o el Instituto Aragonés de Empleo (INAEM).

Comunidad Autónoma del Principado de Asturias. No puede accederse a la información, y aunque se menciona el documento en numerosas páginas web, el mismo no está disponible.

Comunidad Autónoma de Canarias. En su Estrategia de voluntariado 2013-2016, preveía el acercamiento al concepto de Responsabilidad Social Empresarial y al voluntariado corporativo, mediante, entre otros, la sensibilización, concienciación y promoción de la acción voluntaria y del voluntariado corporativo.

Comunidad Autónoma de Castilla La Mancha. Su Borrador del II Plan de Voluntariado, indica que las empresas ofrecen la oportunidad de colaborar de forma interesada con las organizaciones de voluntariado mediante sus propias redes, que tratan de maximizar las funciones sociales de la organización empresarial a través de su estructura mercantil. En este caso, tal y como se enuncia en el documento, existe cierto grado de desconfianza hacia las empresas, y se enuncia del siguiente modo: "El sector voluntario no solo establece relaciones de colaboración con la administración sino también con la empresa privada, si bien en menor medida, y en muchos casos relaciones de competencia. La empresa privada ofrece la oportunidad interesada de realizar acciones conjuntas con las organizaciones de voluntariado, si bien las propias empresas tienden a constituir sus propios espacios de actividad no lucrativa, sin ataduras con las entidades privadas sin ánimo de lucro, tratando de maximizar las funciones sociales de la empresa privada a partir de su estructura social mercantil" (Página 8).

A fin, de mejorar las citadas estructuras el plan se plantea como medidas a implementar, la elaboración de un Compact Disc sobre voluntariado dirigido, entre otros colectivos a las empresas, así como la realización de Seminarios, en colaboración con las mismas, sobre la participación de estas en el sector no lucrativo y de voluntariado. Todo ello con la intención, última, de promover desde la propia Administración autonómica, la acción social de las empresas.

Comunidad Autónoma de Valencia. En el Plan estratégico del voluntariado de la Comunidad Valenciana y plan de acción del voluntariado (2005-2008) se aboga por fomentar la colaboración entre las entidades voluntarias y los agentes implicados, entre ellos se destaca a las empresas. De las que se dice que, desde la nueva ética de la responsabilidad social, deben contribuir a la consecución de los objetivos planteados, como el incremento de la financiación para los proyectos de voluntariado. Para ello se plantea estimular a las empresas por mediación de incentivos diversos como: premios o reconocimientos públicos entre otros.

Comunidad Autónoma de Galicia. Presenta un plan de voluntariado para el año Xacobeo 2021, pero en él no se hace mención expresa al voluntariado de empresas, ni a intervención alguna de estas organizaciones.

Comunidad Autónoma de La Rioja. No puede accederse a la información, ya que, aunque existen referencias al mismo, éste no está disponible.

Comunidad Autónoma de Madrid. La Estrategia de Voluntariado 2017-2021 de esta Comunidad Autónoma, impulsa el apoyo a todo tipo de voluntariado, incluido, expresamente, el corporativo, del que destaca que son las propias empresas las que se involucran en fomentar la participación de su personal empleado. Se prevé que las empresas puedan participar en programas de voluntariado siempre que sean de interés general. Además, a fin de promover y facilitar la participación de sus trabajadores y trabajadoras en actividades de voluntariado, contempla la adopción de medidas de reducción de jornada o de adaptación de la misma, suspensiones, con derecho a reserva de puesto de trabajo, ya sean retribuidas o no. Si bien, se observa, asimismo, la participación de otros agentes vinculados con la misma, como personal jubilado, accionistas, o empresas proveedoras. Esta estrategia, destaca, también, por recoger una clasificación de tipos de voluntariado, entre los que se incluye el voluntariado corporativo, como se puede ver en la Figura 1. Además, de por contener la definición expresa del voluntariado corporativo, indicando que es aquel "promovido por una empresa o institución que propicia la participación en actividades de voluntariado de las personas relacionadas con ella (trabajadores, clientes, antiguos colaboradores, etcétera)" (Dirección General de Servicios Sociales e Integración Social, 2017). 
Tabla. 3. Categorías de voluntariado previstas en la Estrategia de voluntariado 2017-2021, de la Comunidad de Madrid.

\begin{tabular}{|l|}
\hline • Voluntariado social. \\
\hline - Voluntariado internacional de cooperación para el desarrollo. \\
\hline - Voluntariado ambiental. \\
\hline - Voluntariado deportivo. \\
\hline - Voluntariado educativo. \\
\hline - Voluntariado socio-sanitario. \\
\hline - Voluntariado de ocio y tiempo libre. \\
\hline - Voluntariado corporativo. \\
\hline - Voluntariado comunitario. \\
\hline - Voluntariado de protección civil. \\
\hline - Voluntariado universitario. \\
\hline
\end{tabular}

Fuente: Elaboración propia con base en Dirección General de Servicios Sociales e Integración Social (2017)

En la estrategia se menciona no sólo a las empresas tradicionales, sino, también, a las entidades sociales, de las que se dice que incorporan una óptica social, y de interés general a su noción de generar valor. Para todas ellas la Comunidad de Madrid prevé la implantación de medidas de participación e implicación, a fín de incentivar y promocionar la participación ciudadana, y generar una sociedad más solidaria, activa y transformadora, entre otras.

Comunidad Foral de Navarra. En su Plan de acción de voluntariado 2018-2020, propone establecer un servicio de promoción e intermediación empresas-organizaciones sociales, a fin de incentivar las relaciones de colaboración entre ambas instituciones. Para lo que se desarrollarán bases de datos de empresas, fomentarán actividades o espacios para el intercambio entre empresas y entidades sociales, entre otras actuaciones. Mientras, en la Estrategia Navarra de voluntariado, la empresa se convertirá en un agente más del voluntariado, a través de la responsabilidad social corporativa. Así, el recogido como voluntariado de personal empleado hace que las entidades empresariales acaban asumiendo responsabilidades con la sociedad, además de garantizar la rentabilidad para sus inversores/as. Para ello se plantea que podrán apoyar a las personas voluntarias individualmente, o mediante la generación de programas de voluntariado que se integrarán en las estrategias empresariales, o, mediante donaciones económicas. No obstante, el propio texto reconoce que este tipo de iniciativas resultan complejas en el tejido industrial navarro para lo que propone la colaboración de la Cámara de Comercio de Navarra, e incide en la importancia de que se establezca un marco de cooperación en el que se impongan la equidad, el diálogo, la transparencia, el respeto mutuo y la colaboración, aunque se incluye como una amenaza la percepción de este tipo de relaciones, sector no lucrativo-sector privado, que se considera complicada, por las reticencias mutuas.

Comunidad Autónoma del País Vasco. En la Estrategia vasca del voluntariado 2017-2020, se plantea fomentar el diálogo con la empresa, a fin de propiciar un acercamiento entre la participación social y la solidaridad de las empresas que permita explorar las posibilidades de voluntariado vinculado a empresas, sector público,...

En la Tabla 4 se recogen todas aquellas comunidades autónomas españolas con normativa y con planes estratégicos sobre voluntariado de personal empleado. Como se puede apreciar, existe normativa que no está asociada con tener un plan estratégico y viceversa. De la misma se destaca que no coinciden las comunidades que contemplan el fenómeno del voluntariado de empresas en su legislación, y en sus planes. Así Andalucía, Aragón, Canarias y Madrid, lo contemplan tanto en la normativa como en los planes estratégicos, mientras que Cataluña, Galicia e Islas Baleares, lo abordan en el ámbito legal, y Castilla la Mancha, Comunidad Valenciana, Navarra y País Vasco, únicamente hacen referencia al voluntariado en sus planes o estrategia de 
voluntariado. De lo anterior se concluye que once de las diecisiete comunidades autónomas contemplan actuaciones o medidas vinculadas con la estrategia objeto de este estudio.

Tabla. 4. Comunidades Autónomas que contemplan el voluntariado de personal empleado en la norma o en los planes estratégicos

\begin{tabular}{|c|c|c|}
\hline & Normativa & Planes Estratégicos \\
\hline Andalucía & $\mathrm{Si}$ & Sí \\
\hline Aragón & $\mathrm{Si}$ & Sí \\
\hline Asturias & No & - \\
\hline Canarias & $\mathrm{Si}$ & Sí \\
\hline Cantabria & No & - \\
\hline Castilla La Mancha & No & Sí \\
\hline Castilla-León & No & - \\
\hline Cataluña & $\mathrm{Si}$ & - \\
\hline Comunidad Valenciana & No & Sí \\
\hline Extremadura & No & - \\
\hline Galicia & $\mathrm{Si}$ & - \\
\hline Islas Baleares & $\mathrm{Si}$ & - \\
\hline La Rioja & No & - \\
\hline Madrid & $\mathrm{Si}$ & Sí \\
\hline Murcia & No & - \\
\hline Navarra & No & Sí \\
\hline País Vasco & No & Sí \\
\hline $\begin{array}{r}\text { Total de Comunidades } \\
\text { Autónomas que sí contemplan el } \\
\text { voluntariado de empresa en sus } \\
\text { distintas normativas sobre } \\
\text { voluntariado }\end{array}$ & 7 & 8 \\
\hline
\end{tabular}

Fuente: Elaboración Propia

\section{Conclusiones}

En este estudio se ha analizado el marco del voluntariado de empresa en el ámbito internacional para después revisar la normativa española de ámbito estatal y de las comunidades autónomas. Es importante que organismos mundiales como la ONU pongan sobre la mesa cuestiones importantes que vienen de la mano de la globalización respecto al voluntariado. Según la mencionada organización, los agentes mundiales, entre los que se encuentran las empresas multinacionales, cada vez participan en mayor medida, en la gobernanzas local y nacional, sin embargo, "muchos de esos agentes no rinden cuentas directamente a las personas que se ven afectadas por sus decisiones" (ONU, 2015). Además, podría ocurrir que los gobiernos carezcan de la 
autoridad necesaria o del poder "para supervisar sus actividades y exigirles responsabilidades" (ONU, 2015). También la Organización Internacional del Trabajo hace aportaciones para que el voluntariado de empresa no utilice el trabajo voluntario de forma indebida. Por otro lado, la Unión Europea ha mostrado numerosas iniciativas para avanzar en el voluntariado corporativo, y hace propuestas para su fomento, especialmente en el caso de las pequeñas y medianas empresas, dado que las grandes suelen tener secciones y medios para dedicarse a la responsabilidad social corporativa. De este modo, no sólo mejora el entorno local, sino también la imagen y reputación de las propias empresas y la satisfacción de sus trabajadores/as ${ }^{29}$.

En cuanto al marco jurídico español, se puede concluir que la normativa nacional contempla el concepto de voluntariado de empresa de forma explícita; y la misma situación se da en la generalidad de las comunidades autónomas; en las que se hacen algunas referencias de forma implícita en algunos artículos. Por el contrario, sí existen pautas de organismos internacionales que recogen esta práctica, tanto la Resolución 56/38 de la ONU sobre recomendaciones de apoyo al voluntariado, como las Recomendaciones del Consejo de Europa de 2001 ("Mejora del papel y el estatuto de los voluntarios"), reflejan la necesidad de que los Estados miembros establezcan "marcos fiscales, legislativos y de otro tipo" para aquellas entidades que se dedican a actividades de voluntariado.

Por otro lado, la investigación sobre voluntariado corporativo es esencial para determinar la aportación positiva de las organizaciones "a la sociedad, a la comunidad y el medio ambiente, mediante gestiones de responsabilidad social de forma voluntaria y no solamente por disposiciones legales" (Cuevas-Torres et al., 2015 , p. 266). Además, es preciso seguir avanzando tanto en su delimitación como en su regulación para paliar el posible mal uso que se pudiera hacer por parte de las empresas del voluntariado.

En lo relativo a la normativa autonómica española, hemos comprobado que, de las diecisiete comunidades autónomas españolas, tan solo tres cuentan con una ley de voluntariado posterior a la estatal, en concreto la andaluza, la aragonesa, y la balear. Si bien, la Comunidad de Madrid, con una ley que precede por unos meses a la nacional, destaca como la única que innova su normativa con la inclusión de un apartado específico relativo a la responsabilidad social empresarial y al voluntariado corporativo, ya que no sólo contempla el voluntariado de empresas, o corporativo, sino que enuncia su propia definición, y establece unas pautas básicas a seguir en su aplicación. Este aspecto, hace que consideremos esta ley como precursora en el ámbito de estudio, aunque, su contenido no se tomara en consideración por los legisladores nacionales, en la ley de referencia (Ley 45/2015), puesto que como hemos señalado esta legislación es previa, por unos meses, a la estatal.

Los análisis indican que de las diecisiete comunidades autónomas, once de ellas disponen de normativa en la que se contempla el voluntariado de empresa de forma expresa, o implícita, al mencionar la participación de las entidades empresariales en el voluntariado. Si bien, sólo siete de estas (Andalucía, Aragón, Canarias, Cataluña, Galicia, Islas Baleares y Madrid), lo contemplan en el ámbito normativo, mientras que las demás lo harían en sus planes estratégicos. De la comparación realizada, se puede concluir que en la mayoría de las normativas autonómicas se hace preciso su reforma y adaptación a los avances sociales producidos en materia de voluntariado corporativo, y en la estatal su desarrollo reglamentario.

Además de la normativa sobre voluntariado, han existido planes estratégicos estatales, durante los años previos a la actual normativa, y los hay en algunas comunidades autónomas, pero no existe una correspondencia entre la existencia de plan estratégico al mismo tiempo que legislación, tan solo hemos identificado cuatro comunidades autónomas que cuentan con ambos (Andalucía, Aragón, Canarias y Madrid).

De la búsqueda de referencias al voluntariado en las diferentes comunidades autónomas a través de internet hemos encontrado que hay ocho comunidades que contemplan el voluntariado de empresas en sus planes o estrategias de voluntariado, o al menos se hace mención a la participación de la empresa como organismo propulsor del voluntariado, especialmente, en documentos más antiguos cuando todavía, el concepto de voluntariado corporativo no se había extendido (Andalucía, Aragón, Canarias, Castilla la Mancha, Comunidad Valenciana, Madrid, Navarra y País Vasco). Al analizar su contenido, hemos observado referencias interesantes, como las contempladas por la Comunidad de Madrid, en la que no sólo se contempla el voluntariado corporativo, sino las posibles medidas a adoptar por las entidades empresariales para facilitar la participación de su personal y de otros/as stakeholders relacionados/as con los organismos empresariales vinculados. Otra de las diferencias entre normativas se observa en la Comunidad Foral de Navarra, dónde se llega a determinar la falta de confianza en la relación entre empresa y entidades no lucrativas como una amenaza para su estrategia de voluntariado.

Como propuesta de mejora al marco regulatorio español del voluntariado, se recomienda la inclusión del voluntariado de empresas en su redacción, con su correspondiente definición como se hace con otros tipos de voluntariado, ya que es importante que en el listado de las diferentes modalidades de voluntariado quede

29 Véase el documento de la Comisión al Parlamento Europeo, al Consejo, al Comité Económico y Social Europeo y al Comité de las Regiones, de 20.9.2011, disponible en: https://ec.europa.eu/transparency/regdoc/rep/1/2011/ES/1-2011-568-ES-F1-1.pdf (Consultado el 20 de febrero de 2021). 
clara la delimitación de voluntariado de empresa, al igual que se identifica este tipo de prácticas en otros ámbitos como el medioambiental o el deportivo, por citar alguno de ellos. Y más, cuando hay evidencia de que solamente en las grandes empresas cotizadas españolas, existe un importante volumen de recursos humanos implicados en esta tipología de actividades (Lor-Serrano \& Esteban-Salvador, 2021; MañasViniegra, 2018). Además, podría establecerse una conexión entre el voluntariado corporativo y la Responsabilidad Social Corporativa. Por otro lado, queda sin regular el formato utilizado por las grandes empresas para presentar información sobre voluntariado corporativo en sus informes. En aras a la transparencia sería recomendable que las entidades presentasen una mínima información uniforme y comparable entre ellas para poder valorar su impacto, y en el caso de que así se estime establecer algún tipo de incentivo. Al mismo tiempo, la nueva regulación debería fomentar el voluntariado en las pequeñas y medianas empresas para adaptarse así a las iniciativas de la Unión Europea.

Además de recoger la tipología de voluntariado de empresas, con su oportuna definición, en el posterior desarrollo reglamentario de la Ley 45/2015, sería necesario que se determinaran las pautas básicas para su desarrollo e implantación como hacen los planes estratégicos de las diferentes comunidades autónomas. Para ello se propone la creación de espacios de asesoramiento, como el propuesto por la estrategia de la Comunidad Autónoma de Aragón, o de intercambio entre los distintos agentes implicados, como el recogido en la Estrategia Navarra de Voluntariado, o el establecimiento de medidas que faciliten su desarrollo, como las contempladas por la Comunidad Autónoma de Madrid, en base a reducciones de jornada, o adaptaciones de las mismas.

Por último, se insiste en que resultaría adecuada una mayor regulación del voluntariado de empresa por considerarse un elemento de mejora de la sociedad y de los trabajadores y trabajadoras, dado que su desarrollo está asociado con una gran cantidad de beneficios tales como la satisfacción laboral o el desarrollo de nuevas capacidades del personal. Asimismo, como recomienda la ONU, sería conveniente la introducción de incentivos fiscales y subvenciones para las organizaciones que apliquen estas prácticas, a fin de incentivar y estar más cerca del bien común, y de todos y todas stakeholders implicados/as.

\section{Referencias bibliográficas}

Allen, K. (1989) Creating a corporate volunteer community. The Philanthropis, 24(43), pp. 221-239.

Allen, K. (2011) LA GRAN CARPA Voluntariado corporativo en la era global Fundación Telefónica (Ariel y Fundación Telefónica (ed.)).

Aranguren Gonzalo, L. (2001) Políticas de voluntariado. Órgano de Expresión Del Instituto Emmanuel Mounier Política \& Economía, 3-4.

Baviera, I. (2014) Situaciones de empleo irregular y fraude a la Seguridad Social en los trabajos de voluntariado. IUS CANONICUM, 54 (108), pp. $639-662$. http://search.ebscohost.com/login.aspx?direct=true\&db=a9h\&AN=100211192\&lang=es\&site=ehost-live.

Benjamin, E. (2001) A look inside corporate employee volunteer programs. The Journal of Volunteer Administration, 19 (2), pp. 16-32.

Benlloch Sanz, P. (2017) Aproximación socio-laboral a la Ley de 45/2015 de 14 de octubre de voluntariado. Revista Española de Derecho Del Trabajo, № 195, pp. 139-163.

Bowen, G. A., Burke, D. D., Little, B. L., \& Jacques, P. H. (2009) Comparison of Service-Learning and Employee Volunteering Programs. Academy of Educational Leadership Journal, 12 (3), pp. 1-16.

Caligiuri, P., Mencin, A., \& Jiang, K. (2013) Win-Win-Win: The Influence of Company-Sponsored Volunteerism Programs on Employees, NGOs, and Business Units. Personnel Psychology, 66 (4), pp. 825-860. https://doi.org/10.1111/peps.12019.

Cosenza, J. P., Gil, M. I. S., \& Alegría, A. I. Z. (2018) Corporate Volunteering: a Tool for Promoting a Strategy for Internal Corporate Social Responsibility Integrating Retirees. Revista Kairós : Gerontologia, 21 (4), pp. 161-189. https://doi.org/10.23925/2176-901x.2018v21i4p161-189.

Cuevas-Torres, M., Marín, J., Pérez, T., Blanco, S., \& Torres, D. (2015) Estudio de caso: Razones para fomentar el Voluntariado Corporativo en tres Organizaciones en Puerto Rico. Revista Puertorriqueña de Psicología, 26 (2), pp. 254-268.

Dirección General de Servicios Sociales e Integración Social. (2017) Estrategia De Voluntariado De La Comunidad De Madrid 2017 - 2021. https://www.ucm.es/data/cont/docs/1355-2017-12-20-estrategia de voluntariado_20172021 0.pdf.

Fundación Adecco. (2011) Estudio sobre el estado del voluntariado corporativo en España 2010. El valor del Voluntariado Corporativo para la empresa y sus colaboradores.

Garcia Nieto, M. T. (2012) El voluntariado corporativo. Un modelo de responsabilidad empresarial para el desarrollo social. CIC. Cuadernos de Información y Comunicación, $\mathrm{N}^{\mathrm{o}} \quad 17, \quad \mathrm{pp} . \quad 287-302$. https://doi.org/10.5209/rev_ciyc.2012.v17.39269.

Graff, L. (2004) Making a business case for employer-supported volunteerism. 
Grant, A. M. (2012) Giving time, time after time: Work design and sustained employee participation in corporate volunteering. Academy of Management Review, 37 (4), pp. 589-615. https://doi.org/10.5465/amr.2010.0280.

Habisch, A., Schmidpeter, P. H., \& Meister, R. (2001) Corporate Citizenship as investing in social capital. Logos Verlag Berlin.

Lemonche, P. (2011) Voluntariado corporativo un Puente de colaboración entre la empresa y la sociedad (Forética (ed.); Forética). Forética.

Lor-Serrano, A., \& Esteban-Salvador, L. (2021) An Approach to Corporate Volunteering in Spain. Social Sciences, 10(3), pp. 1-19. https://doi.org/https://doi.org/10.3390/socsci10030080.

Mañas-Viniegra, L. (2018) El voluntariado corporativo en la estrategia de responsabilidad social de las empresas del IBEX 35. Retos, 8(16), pp. 19-32. https://doi.org/10.17163/ret.n16.2018.02.

Martínez Ripoll, J. M. (2017) Voluntariado y empleo precario: Dos caras del Tercer Sector de Acción Social. Trabajo Social Hoy, No 80, pp. 61-72. https://doi.org/10.12960/tsh.2017.0004.

Ministerio de Sanidad Política Social e Igualdad. (2010) Estrategia Estatal del Voluntariado 2010-2014 Aprobada por Acuerdo del Consejo de Ministros del 23 de diciembre de 2010 (p. 35).

Moon, J. (2001) Business Social Responsibility: A Source of Social Capital? Reason in Practice, 1(3), pp. 35-45.

Muthuri, J., Moon, J., \& Matten, D. (2006) Employee Volunteering and the Creation of Social Capital (No. 34-2006 ICCSR Research Paper Series-ISSN 1479-5124).

OIT. (2011) Manual de medición del trabajo voluntario (1st ed.). http://www.ilo.org/wcmsp5/groups/public/--dgreports/---dcomm/---publ/documents/publication/wcms_167833.pdf.

ONU. (2015) Informe sobre el estado del voluntariado en el mundo: transformar la gobernanza (C. D. Incorporated (ed.)).

Peloza, J., \& Hassay, D. N. (2006) Intra-organizational Volunteerism: Good Soldiers, Good Deeds and Good Politics. Journal of Business Ethics, 64(4), pp. 357-379. https://doi.org/https://doi.org/10.1007/s10551-005-5496-z.

Points of Light Foundation. (2007) The promise employee skill-based volunteering holds for employee skills and nonprofit partner effectiveness: A review of current knowledge. July.

Ruizalba, J. L., Vallespín, M., \& González-Porras, J. L. (2014) El voluntariado corporativo y sus efectos sobre la satisfacción laboral y el compromiso en empresas familiares de Andalucía. Revista de Empresa Familiar, 4(1), pp. 45-58.http://sfx.cranfield.ac.uk/cranfield?url_ver=Z39.88-

2004\&rft_val_fmt=info:ofi/fmt:kev:mtx:journal\&genre=article\&sid=ProQ:ProQ\%253Aabiglobal\&atitle=El+volunt ariado+corporativo+y+sus+efectos+sobre+la+satisfacci $\% 25 \mathrm{C} 3 \% 25 \mathrm{~B} 3 \mathrm{n}+\mathrm{laboral}+\mathrm{y}+\mathrm{el}+\mathrm{compromiso}+\mathrm{en}+\mathrm{empresas}$.

Sajardo Moreno, A., \& Ribas Bonet, M. A. (2014) La inversión social de las empresas: el voluntariado corporativo en España. CIRIEC-España, Revista de Economía Pública, Social y Cooperativa, No 80, pp. $161-186$. http://www.ciriec-revistaeconomia.es/banco/CIRIEC_8007_Sajardo_Ribas.pdf.

Saz Gil, M. I., \& Zardoya Alegría, A. I. (2014) gestión del voluntariado corporativo en las organizaciones no lucrativas. Revista Española Del Tercer Sector, № 28, pp. 81-98.

Valor Martínez, C. (2002). Donaciones y Marketing causa: Influencia en la decisión de compra. Revista de Investigación y Marketing, $\mathrm{N}^{\mathrm{o}}$ 81, pp. 57-70. http://www.aedemo.es/aedemo3/socios/revista81/Ad-81-10.pdf.

\subsection{Legislación}

IV Plan andaluz del voluntariado 2017-2020 (consulta: 2 marzo 2021). Disponible: https://www.juntadeandalucia.es/export/drupaljda/publicacion/17/10/121017_IV\%20Plan\%20Andaluz\%20del\%20V oluntariado\%202017-2020.pdf.

Borrador, II Plan de voluntariado de Castilla-La Mancha (consulta 2 marzo 2021). Disponible:: http://observatoritercersector.org/pdf/recerques/Plancastillalamancha.pdf.

Decreto 59/2000, de 26 de julio, por el que se regula el voluntariado cultural en Cantabria. Boletín Oficial de Cantabria, 7 de agosto de 2000, núm. 152, páginas 5803 a 5805 .

Decreto 30/2003, de 18 de febrero, de funcionamiento del Consejo Vasco del Voluntariado. Boletín Oficial del País Vasco, 27 de febrero de 2003, núm. 42, páginas 2965 a 2968.

Decreto 53/2003, de 30 de abril, por el que se crea la Comisión Regional de Voluntariado de Castilla y León. Boletín Oficial de Castilla y León, 7 de mayo de 2003, núm. 85, páginas 6630 a 6632.

Decreto 123/2003, de 6 de mayo, por el que se aprueba el I Plan andaluz del voluntariado en Andalucía. Boletín Oficial de la Junta de Andalucía, 4 de junio de 2003, núm. 105, páginas 11918 a 11941.

Decreto 1/2019, de 17 de enero, por el que se regulan las organizaciones de voluntariado de Protección Civil de Cantabria y el Registro de Organizaciones de Voluntariado de Protección Civil. Boletín Oficial de Cantabria, 25 de enero de 2019, núm. 18, páginas 1578 a 1603.

Estrategia aragonesa de voluntariado (consulta 2 marzo 2021). Disponible: http://aragonparticipa.aragon.es/sites/default/files/presentacion_estrategia_aragonesa_de_voluntariado.pdf.

Estrategia canaria de voluntariado 2013-2016 (consulta 2 de marzo 2021). Disponible: https://www.gobiernodecanarias.org/cmsweb/export/sites/derechossociales/voluntariado/.content/PDF/Anexo_infor me_estrategias_definitivas.pdf. 
Estrategia de voluntariado de la Comunidad de Madrid 2017-2021 (consulta 2 marzo 2021). Disponible: https://www.comunidad.madrid/transparencia/sites/default/files/plan/document/estrategia_de voluntariado_20172021 0.pdf.

Estrategia Navarra de voluntariado (consulta 4 marzo 2021). Disponible: http://www.navarra.es/NR/rdonlyres/C22143CC-B140-42E2-A9F5-62679594FEC4/303113/080115ps81.pdf.

$\begin{array}{llllllll}\text { Estrategia vasca del voluntariado } & 2017-2020 & \text { (consulta } & 2 & \text { marzo } & 2021) . & \text { Disponible: }\end{array}$ https://www.euskadi.eus/contenidos/informacion/estrategia_voluntariado_2017/es_def/adjuntos estrategiavascadelvoluntariado_es.pdf.

Ley 4/1995, de 16 de marzo, de voluntariado en Castilla-La Mancha. Boletín Oficial del Estado, 5 de marzo de 1996, núm. 56, páginas 8663 a 8667.

Ley 1/1998, de 5 de febrero, reguladora del voluntariado social en Extremadura. Boletín Oficial del Estado, 2 de abril de 1998, núm 79, páginas 11243 a 11245.

Ley Foral 2/1998, de 27 de marzo, del voluntariado. Boletín Oficial del Estado, 2 de junio de 1998, núm. 131, páginas 18079 a 18084.

Ley 4/1998, de 15 de mayo, de voluntariado de Canarias. Boletín Oficial del Estado, 5 de junio de 1998, núm. 134, páginas 18678 a 18684 .

Ley 7/1998, de 6 de mayo, del voluntariado de la Rioja. Boletín Oficial del Estado, 26 de mayo de 1998, núm. 125, páginas 17319 a 17323.

Ley 17/1998 de 25 de junio1998, del voluntariado de la Comunidad Autónoma del País Vasco. Boletín Oficial del Estado, 31 de diciembre de 2011, núm. 315, páginas 147222 a 147230.

Ley 4/2001, de 19 de junio, del voluntariado. Boletín Oficial del Estado, 13 de julio de 2001, núm. 167, páginas 25426 a 25432.

Ley 10/2001, de 12 de noviembre, del voluntariado del Principado de Asturias. Boletín Oficial del Estado, 11 de enero de 2002, núm. 10, páginas 1247 a 1252.

Ley 5/2004, de 22 de octubre, del voluntariado en la Región de Murcia. Boletín Oficial del Estado, de 20 de agosto de 2005, núm. 199, páginas 29078 a 29085.

Ley 8/2006, de 10 de octubre, del voluntariado en Castilla y León. Boletín Oficial del Estado, 21 de noviembre de 2006, núm. 278, páginas 29078 a 29085.

Ley 10/2011, de 28 de noviembre, de acción voluntaria de Comunidad Autónoma de Galicia. Boletín Oficial del Estado, 14 de enero de 2012, núm. 12, páginas 2440 a 2460.

Ley 1/2015, de 24 de febrero, del voluntariado en la Comunidad de Madrid. Boletín Oficial del Estado, 3 de junio de 2015, núm. 132, páginas 47098 a 47106.

Ley 25/2015, de 30 de julio, del voluntariado y de fomento del asociacionismo de la Comunidad Autónoma de Cataluña. Boletín Oficial del Estado, 9 de septiembre de 2015, núm. 216, páginas 79297 a 79314.

Ley 4/2018, de 8 de mayo, andaluza del voluntariado. Boletín Oficial del Estado, 25 de mayo de 2018, núm. 127, páginas 54412 a 54436.

Ley 6/2018, de 28 de junio, del voluntariado de Aragón. Boletín Oficial del Estado, de 29 de agosto de 2018, núm. 209, páginas 85314 a 85339 .

Ley 11/2019, de 8 de marzo, de voluntariado de las Illes Balears. Boletín Oficial del Estado, 13 de abril de 2019, núm. 89 , páginas 39032 a 39050.

Ley 6/2019, de 29 de marzo, de participación y promoción juvenil del Principado de Asturias. Boletín Oficial del Estado, 27 de mayo de 2019, núm. 126, páginas 56063 a 56092.

Plan de acción voluntariado 2018-2020 (consulta 2 marzo 2021). Disponible: https://solidaridadintergeneracional.es/files/biblioteca/documentos/plan_accion_voluntariado_20182020_navarra.pdf.

Plan de voluntariado para o Xacobeo 2021 (consulta 2 marzo 2021). Disponible: https://voluntariadogalego.org/sites/default/files/2021-01/Plan_voluntariado_Xacobeo21_V3_compressed-

2_DEF_1.pdf

Plan estratégico del voluntariado de la Comunidad Valenciana y plan de acción del voluntariado (2005-2008) (consulta 2 marzo 2021). Disponible: http://www.iniciativasocial.net/legis/plan_estrategico_vol_0508.pdf. 